\title{
A mixed-method study of edible oil waste from farm to table in Iran: SWOT analysis
}

\author{
Y. Salmani ${ }^{1} \cdot$ F. Mohammadi-Nasrabadi ${ }^{1} \cdot$ F. Esfarjani $^{1}$
}

Received: 25 April 2021 / Accepted: 9 September 2021 / Published online: 23 September 2021

○) Springer Japan KK, part of Springer Nature 2021

\begin{abstract}
The increasing trend of food waste is one of the serious challenges throughout the world. The purpose of this study is to investigate the status of edible oil waste (EOW) from farm to table using the SWOT (strengths, weaknesses, opportunities, and threats) analysis in Iran (2021). First, semi-structured, interviews were conducted with 11 experts in the edible oil industry. Then a cross-sectional study was done on 40 restaurant managers through telephone interviews about the restaurant's discarded edible oils. Finally, an online study was undertaken among 121 households regarding their waste cooking oil at home. Two categories in five themes with 20 subthemes were explored based on the participant's perspectives. Lack of upto-date knowledge and appropriate technology were the main reasons for making waste from farm to factory. EOW is used optimally in other industries. The results showed that $92 \%$ of the restaurants sell the EOW for poultry feeds without refinement. The majority of the households [52\%] throw EOW in the garbage and 21\% dump their discarded oils in the sewage. By SWOT analysis, the challenges of EOW from farm to table were identified. There is no specific policy plan for collecting and recycling EOW. The waste oil used in poultry feed without refinement can enter the human body and the possible oxidation toxicity of this waste can pose public health risks. Policymakers can use the SWOT analysis for setting laws and regulations for EOW to ensure its safe disposal and promote its use for biodiesel to provide a healthy community.
\end{abstract}

Keywords Edible oil waste $\cdot$ Mixed-method $\cdot$ SWOT analysis $\cdot$ Industry $\cdot$ Restaurants $\cdot$ Households

\section{Introduction}

The increasing trend of food waste is one of the serious challenges throughout the world, especially in developing countries; therefore, both politicians and academicians seek to find out ways of edible food waste (EOW) reduction and making optimal use of it [1]. Reducing food loss and waste, in addition to its importance on the food supply of the society, can play an important role in reducing the pressure on resources. In addition, the optimal use of food waste can reduce environmental pollution and prevent the waste of energy-rich sources [2-4].

F. Esfarjani

fesfarjani@hotmail.com

1 Food and Nutrition Policy and Planning Research Department, Faculty of Nutrition Sciences and Food Technology, National Nutrition and Food Technology Research Institute, Shahid Beheshti University of Medical Sciences, Tehran, Iran
The importance of oils and fats, apart from the healthrelated issues, is in their role in commerce and the economy. Plant-derived oils provide substantial promise as a renewable resource for industrial applications [5]. Recently, the worldwide demand and consumption of edible oils have increased rapidly [6]. In 2014, Iran officials reported that the oil and fat consumption per capita is $17 \mathrm{~kg}$ per year [7].

About $90 \%$ of the crude oil used in Iran is imported from other countries [8]. Due to the strong dependence of this industry on imports, reducing oil waste will lead to significant currency saving $[9,10]$. More than half of the imports are in the form of oilseeds. Since there is limited access for all planting-to-harvest processes, greater attention must be paid to the edible oil industry [1]. According to the report from the Iran Ministry of Agriculture in 2017, 13\% of the oilseeds cultured in Iran are wasted [11] from farm to industry, passing through different stages, including harvest, long transport, and handling [12].

It is estimated that the oilseed waste percentage for each commodity group in each step in Asia in production, postharvest, handling, storage and packaging, distribution, and 
consumption is $7,12,8,2$, and $1 \%$, respectively [13]. The issue of improper EOW management is attracting public concern in recent years [14]. About four kg of EOW is produced per person in the Mediterranean countries each year [15].

EOW (especially from the frying process) is generated daily in most restaurants, catering, and households [16]. During the process of food preparation, EOW is produced in restaurants or food factories. Currently, some local restaurants sell the EOW to collectors, who will then export the collected EOW, or sell them to recyclers for industrial purposes, such as the production of biodiesel, or used as materials or additives for other manufacturing processes [17].

Most of the disposed of edible oils come from the households that dispose of them together with other wastes or simply pour them into the drainage [18].

It is stimated that about 16.54 million tons (Mt) of EOW are produced every year among the largest producing countries (China, Malaysia, the United States of America, Europe, Taiwan, Canada, and Japan). Also in Europe, about $0.85 \mathrm{Mt}$ of EOW is produced from the household sector and $0.80 \mathrm{Mt}$ from the commercial sector [19, 20].

In Malaysia, about 800,000 tons of EOW are inappropriately disposed of and end up in the environment, either through direct disposal in drains or through bottling and disposal in the landfill. When released in water, oil increases the chemical oxygen demand with detrimental effects on marine organisms [21].

A recent study in Iran showed that advertising frying foods can increase consumption, and thus, the waste of edible oil at the household level [22].

EOW can be collected and then utilized as a production unit for biofuels, detergents, soap, paints, or lubricants, and rubber manufacturing. The process of collecting and recycling $\mathrm{WCO}$ waste is a solution contribution to reducing waste, reducing dependence on fossil fuel energy, and reducing pollutant emissions [23, 24].

EOW represents a renewable resource for the production of fuel oils and alternative feedstock in replacement for petroleum-based chemicals. Nowadays, because of environmental issues, biodiesel production from the EOW is a very remarkable area for developing countries $[25,26]$.

A SWOT analysis is a technique for generating strategic alternatives from a situation analysis. SWOT stands for strengths, weaknesses, opportunities, and threats [27]. SWOT matrix helps managers or policymakers to develop four types of strategies and provides a framework for identifying and formulating strategies to achieve any specific goals $[28,29]$.

To our knowledge, this is the first mixed-method study to explore the status of EOW from farm to table using the SWOT analysis approach to identify the practical solutions that were proposed for managing the EOW.

\section{Materials and methods}

\section{Study design and subjects}

This is a mixed-method study conducted in three phases on three levels of target groups. The first phase was a qualitative study, whereas the second and third phases were quantitative.

\section{Phase I: stakeholders}

Semi-structured, face-to-face interviews were conducted in the first phase with 11 experts in the field of the edible oil industry.

\section{Sample selection}

The participants were recruited through purposive sampling and snowball methods. The interviews were continued until reaching data saturation [30]. Open-ended questions were asked to the experts to identify the policy issues of EOW from farm to factory.

The 11 stakeholders (experts in the edible oil industry) in this phase were recognized from the governmental and private sectors, as well as non-governmental organizations as follows: (1) four managers of edible oil factories, (2) one chief executive officer of oils and fats laboratory and the secretary of Iranian Oil Association, (3) three quality control managers of edible oil factories, and (4) three members of the Ministry of Agriculture.

\section{Data gathering}

Before the start of the interviews, the participants were asked to sign a consent form after reading the information sheet. The responses of interviewees were recorded only upon their permission. They were also secured that the collected data would remain private [31]. To protect their identities, every participant was coded. Each interview lasted about one hour. Two interviewers facilitated the interview, one of them led the discussion using open-ended questioning techniques to elicit the participants' views, and the second one summarized, noted, and recorded their audio for doublechecking $[32,33]$. The expert's voices were recorded, fully transcribed, anonymized, and checked for accuracy to obtain categories until generating themes using directed content analysis and constant comparison methods [32]. The interview guide protocol is shown in Table 1.

To enhance trustworthiness, member checking was used and defined as a quality control process by which 
Table 1 Interview guide protocol for stakeholders

Questions
In your opinion:
What are the main reasons for making seed/oil waste from the farm
to the factory?
What are the challenges of EOW from the farm to the factory?
-Harvest and post-harvest
-Imported oilseed
-Factory

a researcher seeks to improve the accuracy, credibility, and validity of what has been recorded during a research interview.

\section{Phase II: restaurant managers}

This cross-sectional study was conducted on a group of randomly selected restaurant managers whose data were obtained from a database of previous studies [34]. Forty restaurant managers were willing to attend this study. Quantitative studies by telephone are well-established in the literature [35]. Qualitative telephone interviews are seen as enhancing access to geographically dispersed participants, increasing the interviewee's privacy, reducing the cost, and enriching the data collection process because the interviewees must be explicit in explaining their points of view, not relying on visual cues, especially during the COVID-19 pandemic [36].

In the present study, telephone interviews were used for asking about.

(1) The participant's demographic information, including gender, age, and educational level.

(2) How much discarded oil is wasted in their restaurant per month?

(3) Do they have any plan for discarded oil in their restaurant?

\section{Phase III: households}

This phase was conducted on the people responsible for purchasing and cooking in the households (aged 20 years and above) who had access to the WhatsApp messenger. To limit the spread of the coronavirus and to minimize any physical contact between the individuals due to restricted out-of-home movement during the data collection, we preferred to use an online survey portal.

\section{Participants}

The online questionnaire's link was sent to five health centers from five districts [North, East, West, South, and Center] of Tehran City through the "WhatsApp" messenger [Facebook, Inc., California, USA]. Each health center invited 50 households to participate in this study through the phone call and informed them about the purpose of the study based on their willingness. In a continuous procedure, 250 individuals were contacted; 185 of them accepted to cooperate and fill out the form. Out of the 185 participants, 64 were excluded because they were not eligible to participate in the study (as they were under 20 years old age or were not responsible for cooking).

\section{Data gathering}

The survey instrument constituted close-ended questions and took approximately $10 \mathrm{~min}$ to complete during the period of 1-15th October 2020. The questions were about

(1) The participant's demographic information, including gender, age, and educational level.

(2) How much discarded oil is wasted in their home per month?

- Does the COVID-19 pandemic affect your consumption of edible oil?

(3) What do they do with discarded (waste) oils of their daily cooking?

\section{- SWOT analysis}

A SWOT analysis is a technique for generating strategic alternatives from a situation analysis, which is used to assist in identifying a strategic direction for an organization. SWOT stands for Strengths, Weaknesses, Opportunities, and Threats. It was preferred for the present work as it yields useful information about the future viability of the considered system. SWOT matrix helps managers or policy makers to develop four types of strategies and provides a framework for identifying and formulating strategies by matching key internal and external factors. The predictive capabilities of the technique come about from the consideration of a system's strengths and weaknesses in the context of the environment, which may present opportunities and threats. Identification of the internal aspects in the trend of EOW includes the advantageous and disadvantageous aspects (characterization of the internal aspects and classifying them into strengths and weaknesses), and identification of the external aspects (characterization of the external aspects and sorting out the opportunities and the threats) $[37,38]$. 


\section{Ethical issues}

This study was approved by the Ethics Committee of National Nutrition and and Food Technology Research Institute (NNFTRI), Shahid Beheshti University of Medical Sciences, Tehran, Iran (Grant no. 190, 1130-7). All respondents were guaranteed anonymity, and all of them provided informed consent.

Table 2 Socio-demographic characteristics of the participants

\begin{tabular}{llll}
\hline Variables & $\begin{array}{l}\text { Stakeholders* } \\
n=11(\%)\end{array}$ & $\begin{array}{l}\text { Restaurant managers } \\
n=40(\%)\end{array}$ & $\begin{array}{l}\text { Households } \\
n=121(\%)\end{array}$ \\
\hline $\begin{array}{l}\text { Gender } \\
\text { Male }\end{array}$ & $11(100)$ & $32(80)$ & $5(4)$ \\
Female & 0 & $8(20)$ & $116(96)$ \\
Age (year) & 0 & 0 & $5(4)$ \\
$20-30$ & $1(9.1)$ & $13(32.5)$ & $38(31)$ \\
$30-40$ & $5(45.5)$ & $14(35)$ & $46(38)$ \\
$40-50$ & $3(27.2)$ & $8(20)$ & $24(20)$ \\
$50-60$ & $2(18.2)$ & $5(12.5)$ & $8(7)$ \\
$60 \leq$ & & & \\
Education & 0 & $4(10)$ & $21(17)$ \\
$\leq$ Diploma & $1(9)$ & $14(35)$ & $48(40)$ \\
BSc degree & $5(45.5)$ & $19(47.5)$ & $46(38)$ \\
MSc degree & $5(45.5)$ & $3(7.5)$ & $6(5)$ \\
PhD & & & \\
\hline
\end{tabular}

*Experts in the edible oil industry

\section{Results and discussion}

The socio-demographic characteristics of the participants for each phase are shown in Table 2. At all three levels, the participants were mostly 40-50 years old, and their education level was diploma and above.

According to the results of phase 1, two categories in five themes with 20 subthemes were explored based on the perspectives of the participants (Table 3 ).

\section{Crude oil and oilseed}

Based on the majority of the stakeholder's views, passing through different stages from farm to industry (including harvest, long transport, and handling of oilseeds) leads to oil waste. The majority of the interviewees mentioned the following as the most important reasons for oilseed waste in the harvest stage in Iran:

- Lack of up-to-date knowledge and having poor technical knowledge

- High humidity and unsuitable storage conditions

- Incorrect crop planting location

- Improper processing methods

- Lack of water, overuse of pesticides, and plant diseases

- Lack of attention to indoor cultivation

- Improper harvest time
Table 3 Results of open-ended question [the most important concepts extracted according to priority]

\begin{tabular}{|c|c|c|}
\hline Category & Theme & Subtheme \\
\hline \multirow[t]{9}{*}{ Crude oil and oilseed } & \multirow[t]{8}{*}{ Harvest and post-harvest } & $\begin{array}{l}\text { Lack of up to date knowledge and weak- } \\
\text { ness in technical knowledge }\end{array}$ \\
\hline & & $\begin{array}{l}\text { High humidity and unsuitable storage } \\
\text { conditions }\end{array}$ \\
\hline & & Incorrect location for crop planting \\
\hline & & Improper processing methods \\
\hline & & Lack of attention to indoor cultivation \\
\hline & & $\begin{array}{l}\text { Lack of product quality assurance } \\
\text { system }\end{array}$ \\
\hline & & $\begin{array}{l}\text { Physical and mechanical damage during } \\
\text { harvesting }\end{array}$ \\
\hline & & $\begin{array}{l}\text { Failure to upgrade agricultural machin- } \\
\text { ery due to sanctions }\end{array}$ \\
\hline & Imported oil seeds/crude oil & $\begin{array}{l}\text { Long distance of transportation } \\
\text { Storage tanks } \\
\text { Time-consuming custom clearance }\end{array}$ \\
\hline \multirow[t]{8}{*}{ Factory } & \multirow[t]{4}{*}{ Extraction } & Storage tanks \\
\hline & & Type of oilseed and amount of moisture \\
\hline & & Old refinery equipment \\
\hline & & Pressing stage \\
\hline & Refinery & Saponification \\
\hline & \multirow[t]{3}{*}{ Packaging } & Separation \\
\hline & & Oil type \\
\hline & & Leakage during the filling \\
\hline
\end{tabular}


- Lack of product quality assurance system

- Physical and mechanical damage during harvesting

- Failure to upgrade agricultural machinery due to sanctions

In most developing countries, the percentage of postharvest waste to reach the consumer is much higher than in the pre-harvest stages. According to the report from Iran Ministry of Agriculture in 2017, 13\% of the oilseeds cultured in Iran is wasted [11]. A study in Iran in 2018 showed that the amount of oilseed waste in Iran is high due to lack of proper ventilation in the silos storing oilseeds, lack of up-to-date equipment, use of old production lines, lack of enough financial resources for the timely purchase of grain, lack of adequate support from the private sector, and lack of sufficient competition [25].

Moisture measurement of oilseed is an inevitable operation because it affected the oil extraction and oil waste; in the harvest and almost the whole post-harvest stages such as handling, storage, milling, and oil extraction, we should measure the amount of moisture [39].

On the other hand, long distances, inefficient domestic transportation infrastructure [roads, trucks, and wagons railways], and time-consuming custom clearance process can increase the amount of EOW in imported oilseeds/crude oil.

\section{Oil waste in the factory}

Based on the participant's views, EOW in factory is produced in three main stages:

(1) Extraction: after entering the oil mills, the oilseeds enter the storage tanks, where, by direct drying, the moisture content of the grains falls below $12 \%$ for storage. In this part, waste is usually caused due to high temperature and humidity. Before entering the processing stage, oilseeds must be cleaned of waste products. When cleaning the seeds, some of the seeds are removed together with other materials and wasted. Waste also occurs in the extraction section, which depends on the type of extraction equipment and extraction method. Most of the wastes from oilseeds occur in the pressing stage of extraction [10]. A study in Iran concluded the average waste of 5-6, 4-5, and 3-4\% for sunflower, and canola, and soybean oils, respectively, during the extraction operation [10].

(2) Refinery: based on the interviewees' opinions, the most critical stage of EOW is saponification and separation. Also, the mean of oil loss in refinery factories is under $10 \%$. A study in 2017 reported that the amount of oil waste in this stage is based on oil type, the amount of gum remaining in the oil after extraction, the type, concentration and flow rate of alkali, soap separation conditions, and degumming method [40].
(3) Packaging: due to the obsolescence of the equipment, the main waste of oil at this stage is its leakage during the filling, and the amount of waste in each type of oil is different.

\section{Oil waste in restaurants and fast foods}

The mean EOW of restaurants investigated in this study was $159.4 \mathrm{~kg}$ per month. Most restaurant owners (92\%) said that they have no plan for EOW and sell it, while $28 \%$ said that they dump it in the garbage/sewage. A similar study in China (2013) showed that the largest cooking oil waste producer, fastfood restaurants in large cities, can produce $15 \mathrm{~L}$ of cooking oil waste every day [41].

They mentioned that there is not any specific management for recycling the discarded edible oil. The biggest buyers of discarded oil are illegally private sectors without refinements for poultry feeds.

The use of such oils is only restricted by their chemical composition and provided that the oil's peroxide value is not higher than allowed [42]. However, a recent study in Iran showed that the peroxide content of discarded oils in restaurants was higher than the standard [34]. It seems that due to the high cost of edible oil in Iran, they are overused. Nonrecovered discarded oils in broiler chicken diets could return to our bodies. Initially, EOW should filter and then be directly used in the animal feed [43].

They can also cause some environmental pollution if disposed of illegally, which can cause irreparable damage to the health of the next generation. A similar result from a study in Taiwan (2019) showed that restaurants may sell EOW to illegal collectors [9]. A study in Beijing concluded that $24 \%$ of restaurants do not submit waste cooking oil to formal collectors, and approximately 21.63 thousand tons of waste cooking oil is unaccounted for [44]. A Turkish study in 2011 detected as a problem that waste oil was poured into city pipeline in the restaurant and recommended that education was needed to protect public health and effectively utilize waste frying oils [45]. A study in China showed that there is a correlation between policy incentive effectiveness and restaurant sensitivity to collect waste cooking oil. The study recommended that the government should offer economic incentives to the restaurants in this regard. To guarantee the effectiveness of such policy incentives, supporting laws, policy guidelines, and routine supervision should be provided as well [46].

\section{Oil waste at the household level}

Of 121 respondents, $96 \%$ were female and the majority of them [40\%] had BSc degrees (Table 2). The majority of the participants (84\%) stated there was not any difference between before and after pandemic in their consumption of edible oil. 
The majority of participants in this phase (52\%) said that they throw their EOW in the garbage, $21 \%$ dump it in the sewage, and the rest (27\%) reuse it. Also, most of them (63\%) stated that their consumption of edible oil did not change during the COVID-19 pandemic. However, $27 \%$ of them said that its consumption was decreased in their households and only $10 \%$ of them was increased after emerging of COVID-19.

According to the results of a study in Iran (2019), 22\% of households consume EOW again [47]. A survey in Turkey (2020) showed that edible oils originated from households are mostly disposed of together with other waste [garbage] or simply poured into sewage [18]. Furthermore, clogs of pipes from solidified fats and oils are a common phenomenon and reportedly cost [48].

A study in Italy (2020) showed that, among the participants who were not collecting EOW, $76 \%$ of them disposed of EOW in the sewage and misinformation was the main reason why they did not adhere to the EOW collection program [49]. So, advanced and well-organized collection systems and education are the two most important factors for successful UCO collection from households [20].

It seems that EOW recycling is a free market economy without legal supervision by an adequate waste management system. It is recommended that household hazardous waste disposal companies should be established in Iran to collect EOW. A study in China indicated the positive effects of providing an incentive for participation in waste cooking oil collection [50].

In some countries, an initiative towards EOW recycling is run by the government. For example, in the Czech Republic, in 2020, the municipalities were obligated to allow the separate collection of EOW [51]. To ensure food safety, better manage effluent discharge and promote recycling, some countries and regions in Asia, Europe, and North America have been regulating "waste cooking oils". Regulatory measures include licensing or registration of collectors/disposers of "waste cooking oils", restricting the delivery of "waste cooking oils" to designated disposal facilities only, and keeping complete transaction records [17].

A study in Malaysia in 2015 found that cash incentives to encourage the households' willingness and participation and pricing policy to regulate the price of a kilogram of waste cooking oil were necessary to accept collection and recycling of waste cooking oil [52].

\section{SWOT analysis EOW from farm to table}

The final results of SWOT analysis identified 2 strengths, 10 weaknesses, 6 opportunities and 5 points of threats.
All the data were analyzed to find the internal and external factors to be used as a basis for decision-making strategies to reduce EOW and optimize its use.

\section{Strengths}

Waste oils in factories are sent to other industries to produce fatty acids and esters, industrial additives, de-emulsifiers, soap and detergent, hydraulic brake fluid, metalworking, candles, resin and adhesive, polyamide printing ink for coating paper and calibration, insecticides, fungicides, disinfectants, and decontaminants. Therefore, technical knowledge in the level of factories is acceptable.

\section{Weaknesses}

Old harvesting machines in farms, as well as improper and traditional harvesting, can increase oilseed waste. On the other hand, since $90 \%$ of crude oil or oilseed in Iran is imported from other countries, the long-distance and transportation may cause a lot of oil to be wasted before entering the factory. Imposed sanctions along with mismanagement have increased the cost of purchasing new machinery, modernizing and equipping the factories, and forcing manufacturers to use older machinery, which wastes oil.

At the level of restaurants and households, because of government mismanagement and lack of regulations and laws, there is no plan for collecting EOW. Moreover, due to the high peroxide content of discarded oils in restaurants without proper refinement, using discarded edible oil in poultry feed can cause public health hazards.

In general, the most important barriers to collect and optimize the EOW include:

- Inconsistent laws and regulations

- Lack of appropriate attitude toward food operators

- Poor record of innovation and limited technical expertise to design and build an efficient and effective control system

- Lack of governance structures to coordinate, manage and control

- Lack of EOW collection system

- Lack of social and political attention to this issue

- Lack of political support: policies, priorities, and budget

\section{Opportunities}

Developing free specialized and technical training programs of organizations for farmers can decrease the harvest and post-harvest waste. Public education on EOW collecting in a container may prevent restaurants or households from dumping their used oils in the sewage and the municipality can easily collect them. Creating a proper culture of 
buying, consuming, and maintaining products among consumers, benchmarking of successful models from other countries that allow policymakers to identify gaps in their performance, establishing conversion and complementary industries in the agricultural sector, and making new partnerships for designing recycling system such as producing biodiesel from waste oil are among the other opportunities in this regard.

\section{Threats}

Lack of water, overuse of pesticides, and plant diseases in addition to natural disasters reduce the amount or quality of the crop, and sometimes, destroy it. Another threat is the effect of the imposed economic sanctions against Iran on the value of the bilateral trade of agricultural products between Iran and its trading partners. The sanctions have also caused the factories to be unable to purchase new equipment and so use the old equipment. In the level of restaurants, illegal selling of EOW and using it in the poultry feeds can have a negative effect on human health. In addition, dumping the discarded oils in the sewage can lead to environmental pollution (Table 4).

The implementation of HACCP and ISO 2002 quality control systems in the processing units can help reduce the EOW in the levels of harvesting, post-harvesting, and factories. Furthermore, to reduce the amount of EOW, minimizing the time of customs clearance and the presence of specialists when buying oilseeds or crude oil are recommended. On the other hand, education at the household level to reduce the consumption of frying oils should be pinpointed through different social media.

Overall, the results of this study showed that there is no specific policy for collecting and recycling EOW in Iran; however, EOW can be useful as secondary raw material, if properly managed (Fig. 1). Therefore, it is recommended that, by effective collection and controlled disposal of EOW, the municipality can provide a system for recycling EOW to make local and cost-effective energy (Fig. 2).

Several studies have shown that EOW can cause longterm environmental damage, and thus, increase human health risks; the production of biodiesel from EOW can reduce these problems $[49,53-55]$. On the other hand, the lack of efficient economic incentives and other energy source competitors, as well as a small market for biodiesel can be threats to its development [55]. Biodiesel is advised for use as an alternative fuel for conventional petroleumbased diesel chiefly because it is a renewable and domestic source of energy with an environmentally friendly emission profile and is readily biodegradable.

Table 4 SWOT matrix of the EOW from farm to table

\begin{tabular}{|c|c|}
\hline & Internal factors \\
\hline Strengths & $\begin{array}{l}\text { Waste oils in factories used optimally in other industries } \\
\text { Technical knowledge }\end{array}$ \\
\hline Weaknesses & $\begin{array}{l}\text { Old harvesting, not equipping and not upgrading the structure of farms } \\
\text { Long process for receiving crude oil: purchase, shipment, clearance, and transport from ports to the factories } \\
\text { Old equipment in factories } \\
\text { Mismanagement and leadership problem for collecting waste edible oil } \\
\text { Inconsistent laws and regulation } \\
\text { Lack of appropriate attitude toward food operators } \\
\text { Poor record of innovation and limited technical expertise to design and build an efficient and effective control system } \\
\text { Lack of governance structures to coordinate, manage and control implementation of } \\
\text { EOW collection system } \\
\text { Lack of social and political attention to this issue } \\
\text { Lack of political support: policies, priorities, and budget } \\
\text { External factor }\end{array}$ \\
\hline Opportunities & $\begin{array}{l}\text { Increasing free specialized and technical training programs of organizations for managers and workers of farms } \\
\text { Public education on waste edible oil collecting } \\
\text { Benchmarking of successful models from other countries and making new partnerships for designing recycling sys- } \\
\text { tems and climate change countermeasures } \\
\text { Establishment of conversion and complementary industries in the agricultural sector } \\
\text { Efforts to use waste cooking oil for bio-based plastics and jet fuel } \\
\text { Biodiesel production from waste edible oil }\end{array}$ \\
\hline Threats & $\begin{array}{l}\text { Lack of water, overuse of pesticides, and plant diseases } \\
\text { Sanctions } \\
\text { Change in the political or economic environment } \\
\text { Illegal selling of waste edible oil in the level of restaurants } \\
\text { Dumping their discarded oils in the sewage and environmental pollution }\end{array}$ \\
\hline
\end{tabular}




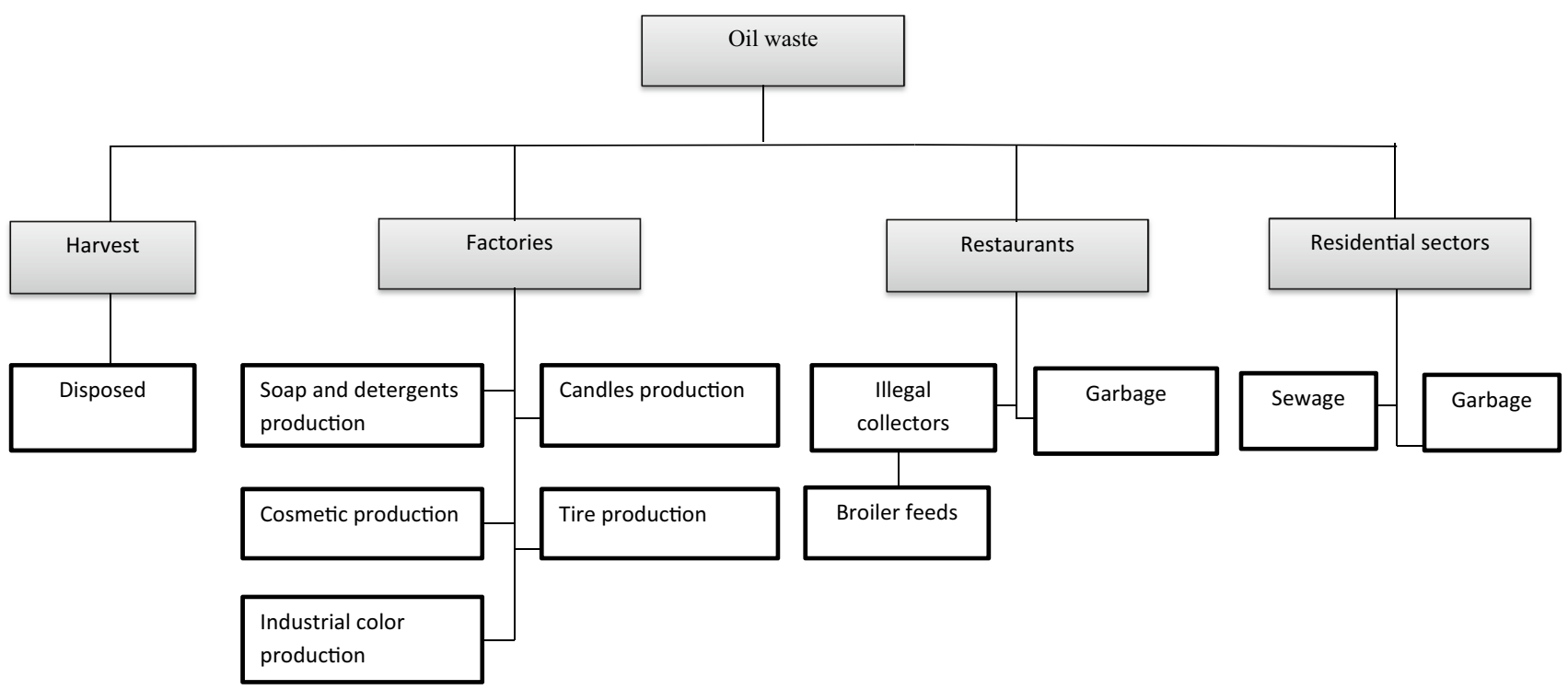

Fig. 1 The derived status of oil waste from farm to table

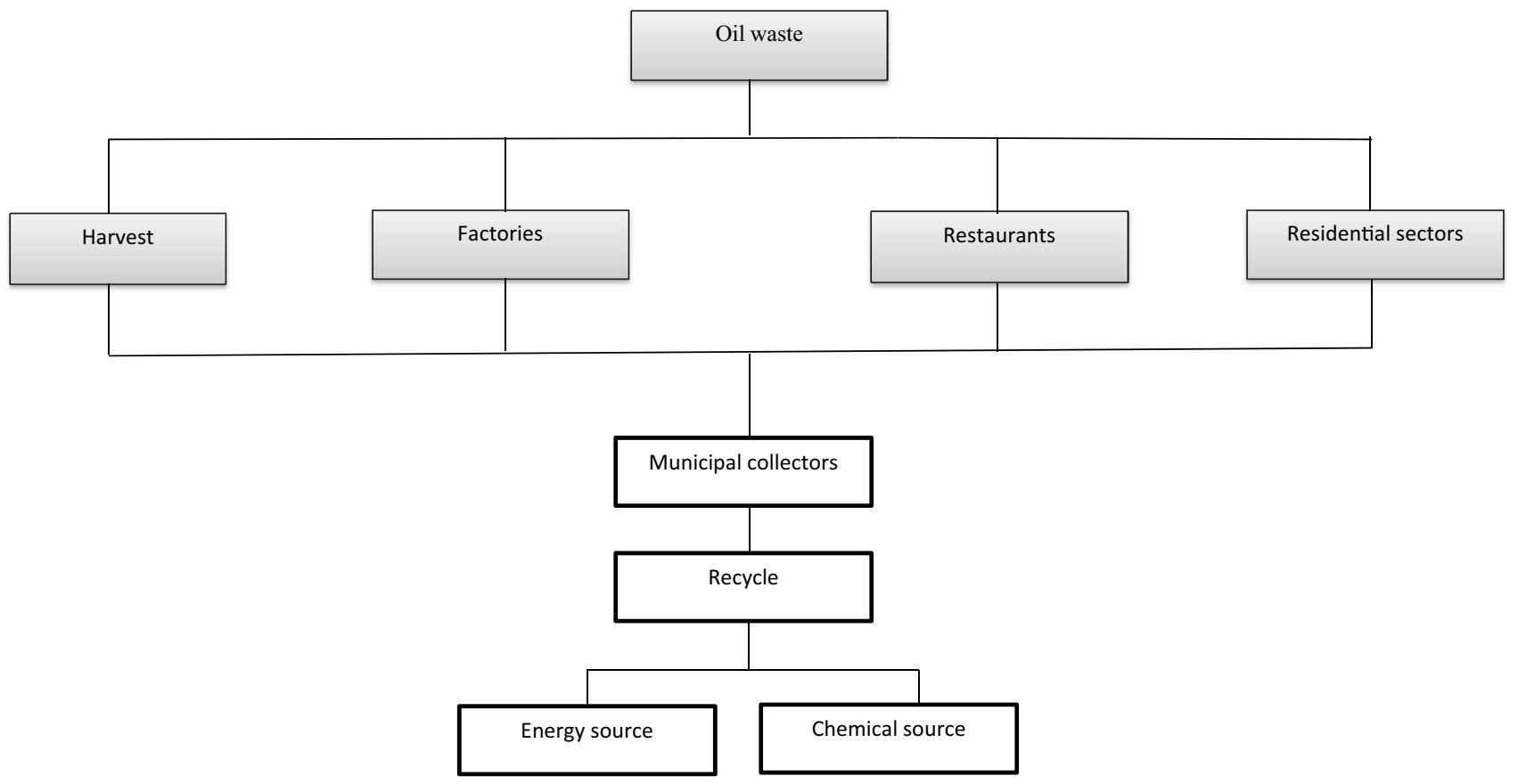

Fig. 2 The suggested model for oil waste from farm to table

\section{Solutions and changes for the future}

Finally, based on SWOT analysis, Table 5 revealed the appropriate strategies and practical solutions for EOW reduction. All the data were analyzed to find the internal and external factors to be used as a basis for decisionmaking strategies to optimize EOW. The most important strategies include: implementation of traceability in supply chain (Invasive strategies), establish the EOW collection centers in cities for households (Competitive strategies), implementation specific licensing system in place for regulating the recycling of EOW (Conservative strategies) establishment of the EOW refinement centers for the future process (Defensive strategies)(Table 5). 
Table 5 Strategies for the EOW from farm to table

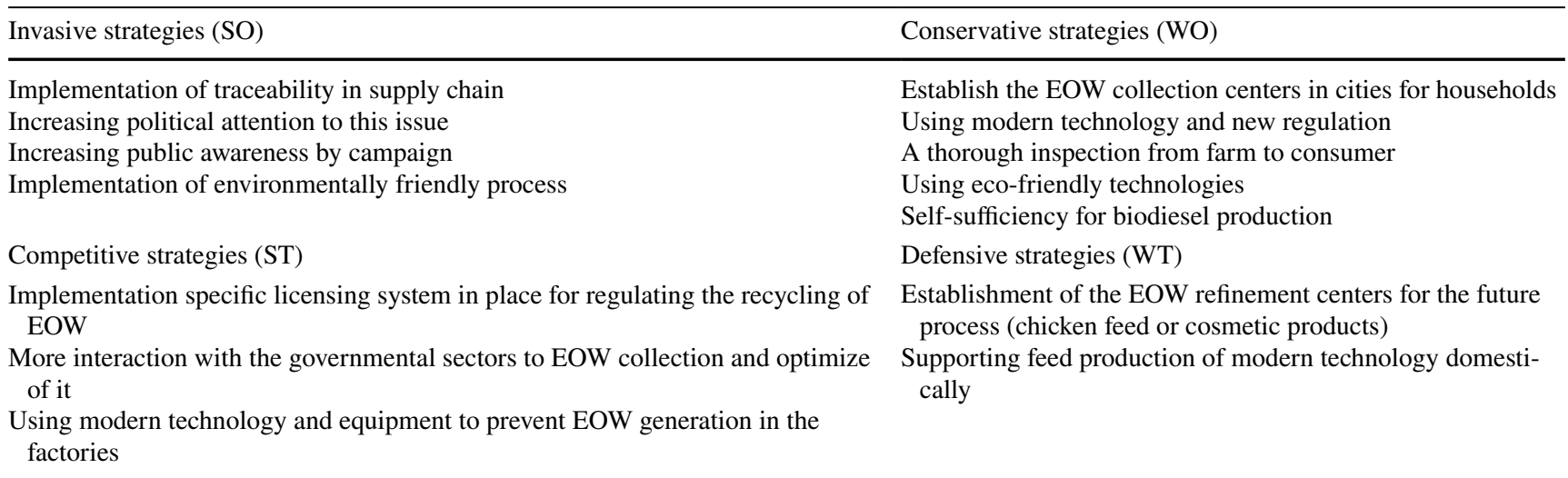

A similar result of this study in Iran stated that due to relatively high obtained yield, biodiesel production from EOW has provided a sound environmental and commercial process [56].

Looking at the recent bibliography related to the EOW mentioned that the modernization in treatment of that includes, not only a research activity on more convenient chemical syntheses, but also the development of new materials, and the definition of new combined treatments, which involve different techniques integrated. Moreover, the integration between academic and industrial research activities will be fundamental to develop recycling treatments that are truly able to substitute existing productions, which involve non-waste raw materials [54].

\section{Conclusion}

The general objectives that should be achieved for the development of the sector, consistent with the EOW, are as follows:

- Modernizing the agriculture sector to optimize productivity within limited resources, and also reduce the costs through investments in the modernization of the farm on an individual basis and in terms of the organization of producers for improved edible oil technology to reduce EOW

- Developing the potential of biodiesel production

We look more in detail at the opportunity (SWOT) provided by the public awareness on waste edible oil collecting which is the major step.

In the end, the SWOT analysis of EOW from farm to table showed that there is no specific plan for recycling EOW. In addition, dumping discarded oil in the sewage can cause environmental degradation and thus human health dangers. The EOW used in poultry feed without refinement can return to the human body and the possible oxidation toxicity of this waste can pose public health risks.

The establishment of factories equipped with convenient facilities together with modernization and structural modification is needed. Also, a coherent and stable network of EOW collection should be created. It is suggested that policymakers set laws and regulations to organize EOW. To create a healthy community, it should be provided economic incentives and education to ensure the safe disposal of EOW to promote its use for biodiesel production which is an environmentally friendly process.

Funding National Nutrition and Food Technology Research Institute, Faculty of Nutrition Sciences and Food Technology, Shahid Beheshti University of Medical Sciences, Tehran, Iran [Grants No. 190, 1130-7].

\section{Declarations}

Conflict of interest All authors declared no personal or financial conflicts of interest.

Ethical approval Ethical issues (including plagiarism, informed consent, misconduct, data fabrication and/or falsification, double publication and/or submission, redundancy, etc.) have been completely observed by the authors. This study was conducted according to the guidelines laid down in the Declaration of Helsinki, and all procedures involving the research study participants were approved by the Research Council of National Nutrition and Food Technology Research Institute. Written informed consent was obtained from all stockholders. Also, they signed a written informed consent form before the interview, and explicit permission was sought from all of them for audio-taping.

\section{References}

1. Abdul Hossein Toutiaei, E.S. (2010), About the correction of consumption pattern, Reduction of product waste Agriculture

2. Reutter B et al (2017) Food waste consequences: environmentally extended input-output as a framework for analysis. J Clean Prod 153:506-514 
3. Munesue Y, Masui T (2019) The impacts of Japanese food losses and food waste on global natural resources and greenhouse gas emissions. J Ind Ecol 23(5):1196-1210

4. Tonini D, Albizzati PF, Astrup TF (2018) Environmental impacts of food waste: learnings and challenges from a case study on UK. Waste Manage 76:744-766

5. Jaworski J, Cahoon EB (2003) Industrial oils from transgenic plants. Curr Opin Plant Biol 6(2):178-184

6. FAO (2017) Crops processed, Food Agric Organ, United Nations

7. Morteza Abdollahi FS (2014) Zahra Abdollahi, optimal food basket for the Iranian society, Andishe Mandegar, Iran

8. Mohammadi, M., et al., Evaluation of oxidative quality parameters in imported edible oils in Iran. British Food Journal, 2013.

9. Tsai W-T (2019) Mandatory recycling of waste cooking oil from residential and commercial sectors in Taiwan. Resources 8(1):38

10. Kebriti M et al (2011) Survey on the rate of losses and wastes in oil seeds processing plants in Tehran Province. J Food Technol Nutr 8(1):42-83

11. Hashtjin AM, Momen RF, Goodarzi F (2016) Reducing agricultural waste as the main strategy in promoting food security.Agricultural Research Education And Extention Organization, 2016 Contract No. 50875. In Persian.

12. Gelderblom W et al (2014) Edible nuts, oilseeds and legumes. Food Safety Management. Elsevier, pp 301-324

13. FAO (2020) Food and agriculture organization of the United Nations. Available from: http://www.fao.org/3/mb060e/mb060 e05.pdf.

14. Yang $\mathrm{R}$ et al (2018) Contract design in reverse recycling supply chain with waste cooking oil under asymmetric cost information. J Clean Prod 201:61-77

15. Hartini, S., D. Puspitasari, and A. Utami (2021) Design of waste cooking oil collection center in Semarang City using maximal covering location problem: a finding from Semarang, Indonesia. in IOP Conference Series: Earth and Environmental Science. IOP Publishing

16. Kheang LS et al (2006) Recovery and conversion of palm oleinderived used frying oil to methyl esters for biodiesel. J Oil Palm Res 18:247

17. Food and Health Bureau et al. (2015) Legislative proposals on regulation of edible fats and oils and recycling of "waste cooking oils"

18. Matušinec J et al. (2020) Cooking oil and fat waste management: a review of the current state. Chemical Engineering Transactions

19. Gui MML, Bhatia S (2008) Feasibility of edible oil vs. nonedible oil vs. waste edible oil as biodiesel feedstock. Energy. 33(11):1646-1653

20. Loizides MI et al (2019) Circular bioeconomy in action: collection and recycling of domestic used cooking oil through a social, reverse logistics system. Recycling. 4(2):16

21. Ka H, Sa K, Aya T (2013) The management of waste cooking oil: a preliminary survey. Health and Environ J. 4:76-81

22. Mohammadi-Nasrabadi F et al (2020) Policy challenges of food advertisements from the viewpoints of Stakeholders: a qualitative study. Food Sci Nutr 8(4):1949-1956

23. Talebian-Kiakalaieh A, Amin NAS, Mazaheri H (2013) A review on novel processes of biodiesel production from waste cooking oil. Appl Energy 104:683-710

24. Silva RFDR (2016) The multi-compartment vehicle routing problem in the collection of recyclable municipal solid waste

25. Zargaraan A et al (2019) Challenges of edible oils from farm to industry: views of stakeholders. Food Nutr Bull 40(1):99-110

26. Karmee SK (2017) Fuel not food-towards sustainable utilization of gutter oil. Biofuels 8(3):339-346

27. Stolovitch HD, Keeps EJ (2006) Handbook of human performance technology: principles, practices, and potential. John Wiley and Sons
28. Dahlan M et al.(2020) Swot analysis of broiler cultivation partnership pattern system in Sumenep District, East Java Province. Int J Sci Res Eng Dev. 3(1): 35-39. Available at: www.jsred.com.

29. Gökhan Unakitan, Abdikoglu Dİ (2016) SWOT analysis of chicken meat sector in Turkey, in Cataloging-In-Publication Data, pp 253-260

30. Guest G, Bunce A, Johnson L (2006) How many interviews are enough? An experiment with data saturation and variability. Field Methods 18(1):59-82

31. Fritz K (2008) Ethical issues in qualitative research. John Hopkins School of Public Health, Department of International Health, U.S.A.

32. Pope C, Mays N (2020) Qualitative research in health care, Wiley Online Library

33. Taylor SJ, Bogdan R, DeVault M (2015) Introduction to qualitative research methods: a guidebook and resource. John Wiley and Sons

34. Esfarjani $\mathrm{F}$ et al (2019) Evaluating the rancidity and quality of discarded oils in fast food restaurants. Food Sci Nutr 7(7):2302-2311

35. Carr EC, Worth A (2001) The use of the telephone interview for research. NT Res 6(1):511-524

36. Trier-Bieniek A (2012) Framing the telephone interview as a participant-centred tool for qualitative research: a methodological discussion. Qual Res 12(6):630-644

37. Gürel E, Tat M (2017) SWOT analysis: a theoretical review. J Int Soc Res 10(51):994-1006

38. Leigh D (2009) SWOT analysis. Handbook of improving performance in the workplace: 1-3: 115-140

39. Soltani MTA, Alimardani R (2014) Moisture content determination of oilseeds based on dielectric measurement. CIGR 16(1):313-318

40. Kozyuk O, Reimers P (2017) Method for reducing neutral oil losses during neutralization step, Google Patents

41. Abdullah NH, Hasan SH, Yusoff NRM (2013) Biodiesel production based on waste cooking oil (WCO). Int J Mater Sci Eng 1(2):94-99

42. Dorra T, Hamady G, Abdel-Moneim M (2014) The use of recovered frying oil in broiler chicken diets: effect on performance, meat quality and blood parameters. Res J Animal Vet Fishery Sci 2(3):11-15

43. Panadare DC, Rathod VK (2015) Applications of waste cooking oil other than biodiesel: a review. Iran J Chem Eng 12(3):55-76

44. Liu T et al (2018) Restaurants' behaviour, awareness, and willingness to submit waste cooking oil for biofuel production in Beijing. J Clean Prod 204:636-642

45. Yilmaz E, Buket A (2011) Quantitative assessment of frying oil quality in fast food restaurants. Gida 36(3):121-127

46. Liu T et al (2019) Who is the most effective stakeholder to incent in the waste cooking oil supply chain? A case study of Beijing, China. Energy Ecol Environ 4(3):116-124

47. Salehzadeh $\mathrm{H}$ et al (2019) The type and amount of household oil consumption and the influential factors in Sanandaj city Iran. J Adv Environ Health Res 7(1):1-7

48. Hanisah K, Kumar S, Tajul AY (2013) The management of waste cooking oil: a preliminary study. Health Environ J 4(1):76-81

49. De Feo G et al (2020) Evolution of waste cooking oil collection in an area with long-standing waste management problems. Sustainability 12(20):8578

50. Cho $S$ et al (2015) Incentives for waste cooking oil collection in South Korea: a contingent valuation approach. Resour Conserv Recycl 99:63-71

51. Van Fan Y et al (2020) Implementing circular Economy in municipal solid waste treatment system using P-graph. Sci Total Environ 701:134652

52. Yacob MR, Kabir I, Radam A (2015) Households willingness to accept collection and recycling of waste cooking oil for biodiesel 
input in Petaling District, Selangor Malaysia. Procedia Environ Sci 30:332-337

53. Khan HM et al (2020) Sustainable biodiesel production from waste cooking oil utilizing waste ostrich (Struthio camelus) bones derived heterogeneous catalyst. Fuel 277:118091

54. Mannu A et al (2020) Available technologies and materials for waste cooking oil recycling. Processes 8(3):366

55. Liu Y et al (2018) A SWOT analysis of biodiesel production from waste cooking oil. IOP Conf Ser Earth Environ Sci (IOP Publishing) 170:022136
56. Ebrahimi S, Najafpour GD, Ardestani F (2017) Transesterification of waste cooking sunflower oil by porcine pancreas lipase using response surface methodology for biodiesel production. Appl Food Biotechnol 4(4):203-10

Publisher's Note Springer Nature remains neutral with regard to jurisdictional claims in published maps and institutional affiliations. 